\title{
Structure-based optimization and discovery of novel 1,3,5-triazine derivatives as bacterial translation inhibitor with favourable metabolic fate
}

\author{
UP Singh*, JK Srivastava, HR Bhat \\ From 3rd International Conference on Prevention and Infection Control (ICPIC 2015) \\ Geneva, Switzerland. 16-19 June 2015
}

\begin{abstract}
Introduction
We have recently moved into an era not just of multiple resistant bacteria but of totally resistant pathogens, which now include vancomycin-resistant enterococci, carbapenemresistant Acinetobacter baumannii, vancomycin-resistant MRSA and, very recently, NDM-1. Thus, increased incidence of bacterial resistance to currently available antibiotics necessitates the discovery and introduction of new and effective drugs. In our earlier studies, we have discovered a potent antibacterial lead molecule from 1,3,5-triazine (first generation) and its subsequent optimization till its tenth generation results much more advanced analogue with enhanced activity and less toxicity [1].
\end{abstract}

\section{Objectives}

Present study deals with the advancement of novel derivatives of 1,3,5-triazines to increase its efficacy and potency to make them viable drug candidate (eleventh generation).

\section{Methods}

The synthesis of analogues was achieved by means of $\mathrm{S}_{\mathrm{N}} \mathrm{Ar}$ reaction utilizing distinguished amines. These molecules were then subjected to antibacterial screening against pathogenic Gram-positive and Gram-negative micro-organisms. MetaPrint2D-React from University of Cambridge, UK was utilized for the prediction of metabolites of the compounds.

\section{Results}

Entire set of derivatives demonstrated excellent antibacterial activity $\left(1.56-25 \mu \mathrm{g} \mathrm{ml}^{-1}\right)$, and in some instance found equipotent to cefixime as standard. The molecular docking study on eubacterial ribosomal decoding A site (Escherichia coli 16S rRNA A site) confirmed the stability of target compounds into the inner groove of active site by making close $\mathrm{H}$-bonds with highly conserved residues, e.g. Ade38, Gua37, Ade39, and Gua40. Moreover, the most active compound 7e, in MetaPrint2D-React study was not found to be deactivated by human metabolic process, which conform the utility of designed molecules.

\section{Conclusion}

We have discovered an another novel 1,3,5-triazine analogs as potent antibacterial agent through structure-based optimization of our defined lead.

\section{Disclosure of interest}

None declared.

Published: 16 June 2015

\section{Reference}

1. Singh B, Bhat HR, Kumawat MK, Singh UP: Structure-guided discovery of 1,3,5-triazine-pyrazole conjugates as antibacterial and antibiofilm agents against pathogens causing human diseases with favourable metabolic fate. Bioorganic \& Medicinal Chemistry Letters 2014, 24:3321-3325.

\section{doi:10.1186/2047-2994-4-S1-12}

Cite this article as: Singh et al:: Structure-based optimization and discovery of novel 1,3,5-triazine derivatives as bacterial translation inhibitor with favourable metabolic fate. Antimicrobial Resistance and Infection Control 2015 4(Suppl 1):12. 